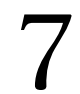

\title{
Graduate attributes for the public good: a case of a research-led university
}

\author{
Susan van Schalkwyk, Nicoline Herman \\ and André Müller
}

\section{The spotlight on graduate attributes}

all (chapter two) and Walker (chapter six) stress the distinction between higher education as a private asset and as a public good. Previously, Walker (2002:43) argued strongly that universities have a role to play in the promotion of democracy and in inculcating the sort of 'cultural capital, values and knowledge' in its graduates that will contribute to a more just and equitable society. This debate is tightly linked to a growing focus on the nature of the attributes students leave university with, including how these attributes will equip graduates for future employment (Barrie, 2007: 439). In South Africa the need for graduates who will be able to participate in growing the national economy was emphasised in the National Plan in Higher Education some ten years ago now (DoE, 2001). More recent mandates emanating from the Department of Higher Education and Training - for example the guidelines provided for aligning programmes with the Higher Education Qualifications Framework (HEQF) - have also included issues of citizenship and social justice (Government Gazette no 30353 2007).

The term 'graduate attributes' appears to have achieved fairly widespread acceptance in recent literature reviewed (Barrie, 2006, 2007, 2009; Hughes and Barrie, 2010), as well as in the South African context (Griesel and Parker, 
2009). Understanding exactly what graduate attributes are, and when and how they ought to be 'developed' is, however, less easily resolved. Bowden et al (2000) have described graduate attributes as 'the qualities, skills and understanding a university community agrees its students should develop during their time with the institution.' Here the focus is on process and a development over time as the student moves from first year through to graduation. For others, however, the emphasis is towards ultimate employability, where 'generic skills' are described as 'the skills, values and attitudes which potential employers might find desirable' (James et al, 2004:2). Graduate attributes are seen to 'include, but go beyond, the disciplinary expertise or technical knowledge...' They are the qualities that also prepare graduates as agents for social good in an unknown future (Bowden et al, 2000). According to Barrie (2004: 262-3), graduate attributes encompass more than 'skills and attitudes'... and should result from the 'usual process of Higher Education', thus via a relevant curriculum which is responsive to the needs of their immediate community, their country and their continent (Jansen, 2009). Students emerge as global citizens (Killick, 2008) with a distinct awareness of the interconnectivity of and networks within the worldwide knowledge ecology (Barnett, 2011:142). Inherent in these understandings is another tension that builds on the competing discourses around the role of the university discussed earlier. From these seeming contradictions, questions emerge: how do (or should) universities respond to the different demands being made on them? What is the impact of these responses, if any?

The way academics understand or interpret graduate attributes is fundamental to any institutional conversation on these issues. Here the work of Barrie (2006:224) is once again instructive. He argues that different conceptions of graduate attributes stand in a hierarchical relationship to one another, with each new conception merging to some extent with its predecessor. He describes 'additive' conceptions which see generic graduate attributes as precursors to university entry - ie what students enter with - or as being complementary to disciplinary learning. On the other hand, he suggests there are transformative conceptions of graduate attributes, where these are seen to interact with other university learning outcomes to facilitate the application of disciplinary knowledge and/or enable learning and knowledge creation. This latter understanding echoes notions of transformative learning 'learning that transforms problematic frames of reference - sets of fixed assumptions and expectations (habits of mind, meaning, perspectives, mindsets) - to make them more inclusive, discriminating, open, reflective and emotionally able to change' (Mezirow, 2003:58). Similarly Waghid, writing 
from a South African perspective, describes the role of university teaching as 'opening students' worlds to critical judgments ... [where] students could perceive things as they could be otherwise' (2005:138). Clearly these understandings would foster graduates for the public good.

However, the diversity that exists across institutions inevitably influences the way in which individual universities are positioned to respond to this mandate. A university's culture, structure, focus and resources (particularly funding) all impact on the way the teaching function is carried out. The attributes that graduates leave an institution with - those that will determine how they enter the world of work and will guide the way they participate in society - are a function of both the university and the individual themselves. Understanding how the individual sees their own development provides an important piece of the puzzle, and we will return to these student perspectives later in this chapter.

Hughes and Barrie (2010:325) have cautioned that graduate attributes must not be seen as additional learning outcomes but as 'inherent in core university and teaching and learning experiences'. Lists of decontextualised skills, they argue, run the risk of being 'perceived ... as having little to do with the type of learning normally associated with higher education' (ibid).

Desired attributes in graduates have been defined on a number of levels. In South Africa, the South African Qualifications Authority (SAQA) formulated a set of 'outcomes deemed critical for the development of the capacity for lifelong learning' (1997). These include being able to think critically and creatively, work in a team, use science and technology effectively and recognise the world as a set of interrelated systems where problem solving contexts cannot exist in isolation. Known as the critical cross-field outcomes (CCFOs), they also referred to developmental outcomes that envisage all learners making an economic and social contribution to society. Typically today, many universities have lists or statements of the attributes they would wish to see in their graduates which, to a greater or lesser degree, mirror what is implied with the CCFOs.

In the previous chapter Walker refers to the crucial role the curriculum plays in advancing human potential and the public good. But how easy is it to execute this transformative role? To explore the variety of perspectives and understandings that have been discussed more directly, we look at Stellenbosch University as a case study. We consider the University's policy statements in relation to graduate attributes and how students' perceptions of these have been experienced by them in the undergraduate curriculum. 


\section{The Stellenbosch University context}

It could be argued that Stellenbosch University (SU) has a healthy learning culture, with many well-established support initiatives that encourage reflective, scholarly teaching and the scholarship of teaching and learning amongst lecturing staff (Van Schalkwyk et al, 2012). Student feedback data, graduate survey information and lecturers' programme reviews appear to point to a positive and meaningful learning experience. As might be expected given that it annually attracts applications from the top academic candidates across the country, the University retains a top position nationally in terms of its undergraduate success rates (DoBE, 2010). It also positions itself as a research-led institution and in recent years has made specific strides in this regard ${ }^{1}$.

SU's vision for teaching described in its Strategic Framework (SU, 2000) reads as follows: 'a university characterised by quality teaching, by the constant renewal of teaching and learning programmes, and by the creation of effective opportunities for learning/study'. Embedded in the learning and teaching policy (SU, 2007a) is the profile of the SU graduate - the outcome of these 'effective learning opportunities'. Accordingly, a graduate of this institution is a person who:

- is well rounded and whose potential has been enhanced to the fullest

- is competent and equipped for professional life

- is adaptable and equipped for lifelong learning

- can play a leadership role in society as a responsible and critical citizen in a democratic social order

- is capable and equipped, through the application of their high-level skills, to play a constructive role in the responsible and sustainable development of the country and society, and who, in so doing, contributes to the wellbeing and quality of life of all people

- is equipped to function effectively in a multilingual context.

The policy adds further substance to one of the central elements of the University's vision: 'gaining national and international standing on the basis of producing graduates who are sought after for their well-roundedness and for their creative, critical thinking. Additional University policy echoes these sentiments. For example, at SU learning materials 'should serve to assist the development of the required graduate attributes, ... broaden students' knowledge and challenge their abilities with reference to the outcomes of the module and programme' (SU, 2007b). More recently, in a draft document entitled Hope as guiding concept for Stellenbosch University (SU, 2011a), hope is described as a leitmotif'for the activities of the University in total, inclusive of 
the creation, transfer and application of scientific knowledge to the benefit of and in interaction with the community...'

It is evident from these examples that the University recognises its responsibility towards its graduates and society. Nevertheless, as a 'historically advantaged' and 'historically white' institution it can influence the way those both within and without the University interpret these intentions. Furthermore, evidence of the manifestation of these ideals is sometimes difficult to find. A recent review of documents submitted as part of a programme renewal process at the institution - which specifically requested that academic departments address aspects of citizenship in their curricula - suggested that engagement with, or even an understanding of what this would mean for curriculum renewal, was limited, as was the awareness as to how to go about it (see also Willey and Gardner, 2007).

\section{The graduates' perceptions}

As part of an institutional initiative to revisit the profile of the SU graduate ten years after its compilation, we sought to gauge graduates' perceptions about the outcomes of their studies at SU. An analysis was conducted of the data generated by an annual graduate exit survey. Known as the Omega questionnaire, the survey was completed electronically by 591 graduates - 17.5 per cent of the total graduating cohort - at the end of 2010 (Du Plessis, 2011). The questionnaire was not originally designed as a test for measuring graduate attributes, and only relevant items were selected for this analysis. This selection was guided by our review of the literature and the existing profile of the SU graduate. The distribution of respondents could be regarded as representative of the University in terms of diversity. Faculty representation was slightly skewed. The grouping of the aggregated responses to the selected questions was conducted according to the six statements in the profile, which provided a student perspective on the extent to which undergraduate studies at the University were promoting the development of the different attributes.

\section{Statements 1-3}

The profile describes graduates as individuals who are 'well rounded and have their potential enhanced to the fullest'; who are 'competent and equipped for professional life'; and who are 'adaptable and equipped for lifelong learning'. According to the results, while being able to work in a group is generally regarded as a key feature of being equipped for professional life, less than half of the respondents (47\%) reported studying in groups during their final year. This figure varied amongst faculties too: in one, 75 per cent of students seemed to 
be doing a considerable amount of group work, while 43 per cent in another larger faculty indicated that they never did group work.

Reflecting on their growth during their period at the University, 90 per cent of graduates said they were now able to see the 'bigger picture' and realised that problems cannot be resolved in isolation. Although extremely positive, this statistic is contradicted by the words of an employer in response to a routine follow up conducted by the University's career office (see Leibowitz, 2011):

Students are quite sheltered, especially coming from small town universities [such as SU] and don't tend to be very savvy. They don't seem to be very informed of how they can apply their studies once they have graduated and struggle to answer questions relating their theoretical knowledge to some of the business questions that ask.

Of the entire group, 97 per cent indicated that their ability to think critically had improved, while 96 per cent reported they were now better able to gather, analyse and organise information. Self-management also appeared to have improved, with over 80 per cent of respondents reporting they had better organisational and time management skills.

Although SU positions itself as a research-led institution, only 20 per cent of the graduates who completed the survey indicated that they often had the opportunity to participate in research activities, while 37 per cent stated that they were never given such an opportunity. In the group as a whole, approximately 50 per cent indicated that it was only sometimes that they had been faced with intellectual challenges.

\section{Statement 4}

According to the profile, graduates 'can play a leadership role in society as a responsible and critical citizen in a democratic social order'. In response to the survey, 72 per cent of the graduating students indicated that they had not participated in any student leadership structures during their years of study, despite the fact that 45 per cent had attended some form of leadership training and 34 per cent reported being satisfied with the leadership opportunities available on campus. Becoming a leader in their respective communities was not something these students seemed to aspire to. Forty-three per cent indicated that this was not important to them while only a small group - 7.45 per cent - felt it was critical. As an indicator race appeared to be significant on several of the responses, and it is notable that becoming a community leader was more important for African and Indian students than for white and coloured students. 


\section{Statement 5}

The profile describes the graduate as 'capable and equipped, through the application of their high-level skills, to play a constructive role in the responsible and sustainable development of the country and society, and who, in so doing, contributes to the wellbeing and quality of life of all people'. In response to a question about their awareness of social challenges facing their community, 77 per cent indicated that they were now more aware of these issues than when they had arrived at the University. Although 82 per cent reported that they were now more aware of social concerns facing South Africa, it was only the theology students - 37.5 per cent - who were involved in voluntary community service to any significant degree, though 75 per cent of all the students indicated that they believed it was important for them to do so.

Eighty three per cent of graduates reported a greater understanding of global issues, with African students proportionately representing the highest number in this group. The same number of respondents felt they became more responsible for the environment - 46 per cent of African students said they had a much higher ability to take responsibility for the environment they live and work in, while 50 per cent felt it was vital for them to become involved in environmental clean-up programmes.

While 86 per cent of students felt it was important to influence social values, 42 per cent of African and 38 per cent of Indian students indicated that it was of the utmost importance. Similarly, all Indian students and 88 per cent of African and coloured students emphasised the importance of helping people. It is interesting, however, that 56 per cent of all students had not acted as a tutor or mentor for fellow students during their final year, and 39 per cent felt they would not really want to be responsible for others in the workplace.

Political awareness, responsibility and participation were seemingly less important issues for the graduates who completed the Omega questionnaire at the end of 2010. Forty three per cent regarded participation in political structures as 'unimportant', while only half of the respondents indicated that they sometimes discussed politics and even fewer felt it was important to stay informed. Forty two per cent had never participated in student elections, although such participation was more important to African students than the others. The unfortunate conclusion that can be drawn is that students are not prepared to be the change they want to see. 


\section{Statement 6}

The profile describes the graduate as 'equipped to function effectively in a multilingual context'. This final statement relates specifically to issues of language. Nevertheless, in the South African context issues of language are often interlinked with those of race. We therefore address both of these issues under this heading.

Despite the University's emphasis on multilingualism, 56 per cent of graduates reported no improvement in terms of using different languages. The fact that only 46 per cent indicated that they had often engaged socially with people from different race groups - a probable statistic given the relative lack of diversity on the University campus, where over 75 per cent of undergraduate students are white - may account for this. Nevertheless, students appeared to recognise this anomaly on the SU campus and close to 83 per cent disagreed with the statement that racial discrimination is not a problem in South Africa. In recognition of this, 42 per cent of African students felt it was vital for them to contribute to racial harmony, in contrast to 41 per cent of white students who regarded a contribution in this area to be only of some importance.

It should be noted, however, that 44 per cent of students thought their ability to get on with people from different races and cultures had improved during their time at SU. In the parallel study referred to earlier, interviews were also conducted with a select group of graduates from previous years (2008 and 2009) and a number of these respondents voiced concerns about this issue (Leibowitz, 2011). The following quote, translated from Afrikaans, offers much insight:

Not at all, definitely not enough cultural diversity. Maties ${ }^{2}$ are at a serious disadvantage in the workplace as far as this is concerned. Young, wonderful, intelligent Maties are sent into the world without having ever expanded their horizons in terms of race and culture. They are not necessarily racist, but they are definitely uninformed. I am worried that we are at worst, defensive, and at best, uncertain in multicultural environments. We simply must find a way to address this.

\section{Academic opportunities towards certain graduate attributes}

A number of items in the Omega questionnaire refer to academic opportunities or attributes that are closely linked with frequently cited graduate attributes. We report on some of these.

Eighty one per cent of graduating students indicated they were satisfied with the quality of teaching at SU. This percentage is fairly consistent across all 
faculties and races. However, when specific aspects of the teaching and learning experience are teased out, some unexpected trends emerge. For example, while 65 per cent of students reported having to write between one and four reports of more than twenty pages in their final year, these responses were clustered among students in the social sciences and humanities.

All students said their writing skills had improved during their years at university. Similarly, students in the humanities report on average 80 per cent enhanced public speaking skills, while in faculties more oriented towards mathematics students felt their mathematical and numerical skills had considerably improved. Interestingly, however, 50 per cent of students in one of the health, science and technology-related faculties felt their mathematical and numerical skills were now poorer than when they had arrived at university.

Finally, 54 per cent of respondents reported that their computer skills were better than when they arrived at university. The activities students performed while working with their computers were not identified.

The graduate responses to the first three statements in the profile highlight notable variations between graduates from different faculties with regard to perceptions of being equipped for professional life and lifelong learning. Leadership and social and political awareness, which form part of statements four and five of the profile, appear to be areas where a great deal of work can be done, particularly if an institution aspires to deliver graduates who can contribute to the public good. The fact that almost half of the respondents had attended some form of leadership training and yet three-quarters said they had not participated in a leadership role suggests a dissonance that requires further investigation. Statement six of the graduate profile deals with language and, in this case, diversity issues. From the students' responses one might argue that graduates are not being exposed to many broader social issues. Finally, the students' responses point to academic experiences that are generally solid, such as those alluded to earlier in the chapter, although some of the faculty differences are of interest and indicate further avenues for enquiry.

While there are many points of congruence, it is clear from this analysis that there are also gaps between the intended graduate outcomes at SU, as formulated in the profile of the University's graduate, and students' perceptions of what they have learned and the opportunities they had. It is further evident that statements of intent such as the University's mission statements and policy documents remain hollow if they do not manifest themselves more 
overtly in relevant, responsive curricula and concomitant co-curricula activities. Equally, it remains incumbent on the institutions themselves to track their graduates as they enter the world of work and citizenship. Such tracking would provide greater insight on the extent to which stated objectives are being met and would enable these institutions to respond appropriately.

\section{Implications}

Musil (2011) has suggested that a university education has the potential to deliver both a private and a public good since students derive personal benefit whilst also contributing to the community. Musil has also argued that 'educating students for generative citizenship cannot be accomplished without recalibrating the curriculum, its pedagogies and the boundaries of faculty work' (2003:8). Graduate attributes are about the learning experiences of students and the objectives we set for our teaching.

As a research-led institution, SU needs to define what this particular identity implies for the graduate attributes of its students. Research-led teaching and involving students in research-like activities are important components of delivering the type of student - an enquiry-focused learner - that is implied in the profile. According to Barrie (2011), one solution to this dilemma might be to have students approach their learning in the same way a researcher approaches their research: actively and critically, questioning and enquiring.

Teaching for the public good then becomes the heart of the institution, its academic programmes, research and faculty work - and thus the defining concepts according to which we teach and learn (Palmer, 1987). This requires a paradigm shift in the way an institution thinks about graduate attributes (knowledge), which leads in turn to a different kind of awareness (attitude/ responsibility) and hereafter to a different way of approaching (action) graduate attributes: the so called 'head, heart, hand approach' described by Johann Pestalozzi (in Soetard, 1994). When lecturers embrace and embed for the public good within their everyday activities of teaching, research and community interaction, it becomes necessary for them to act as role models for their students as civically engaged and thoughtful educators (Levinson, 2011).

\section{Way forward}

As the landscape of higher education changes nationally and internationally and socio-economic and political realities remain, it is opportune for universities, particularly in South Africa, to revisit their role. Re-imagining the sort of graduates a university desires to produce and realigning curricula accord- 
ingly is an important lever in this process. Establishing a renewed or revised set of graduate attributes - specifically those that would contribute to the public good - is clearly only the first step in the process towards producing graduates who actually portray the desired attributes. Inculcating these attributes into the teaching and learning ethos of the university will be a further, equally critical, step. For transformative learning to take place, current programme development activities need to create the space for students and their teachers to critically engage with questions of how graduate attributes are developed during the course of their programme, and which are important in their particular discipline. A shared understanding of what attributes we value in lecturers, how 'hopeful' pedagogies can be developed and what research-led teaching might look like is essential.

But what does this mean for a university that positions itself as research-led? In a commentary on the dearth of African universities in the Times Higher Education Rankings (http://www.timeshighereducation.co.uk/world-univer sity-rankings/2010-2011/africa.html), Goolam Mohamedbhai, a former secretary general of the Association of African Universities and former president of the International Association of Universities, argues that given the challenges facing the African continent, there is no room for universities to focus on rankings: they must direct their attention to research outputs that address the specific needs of the continent. The commodity in which higher education trades is that of knowledge, often generated through research, and it is this that defines the path of a university. The essence of such knowledge, however, is of relevance here. Palmer (1987:22) has argued that 'the way we know has powerful implications for the way we live' and 'every mode of knowing contains its own moral trajectory, its own ethical direction and outcomes', whether these be utilitarian or liberating (Carr, 2009) or anywhere in between. Such is the knowledge that needs to be shared if we are to encourage graduates for the public good.

\section{Notes}

1 Refer http://www.myvirtualpaper.com/doc/stellenbosch-University/research_report/2011031 001/\#0 for details

2 Maties: a colloquial description for Stellenbosch University students

\section{References}

Barnett, R (2011) Being a University. London: Routledge

Barrie, S C (2011) Designing an education for life after university: some strategies. Presentation at the CHEC-PGWC symposium on researching graduate quality. Cape Town. 14 March

Barrie, S C (2009) Academic development as changing social practice: the generic attributes project. In V. Bamber, P Trowler, M Saunders and P Knight (eds) Enhancing Learning, Teaching, 
HIGHER EDUCATION FOR THE PUBLIC GOOD: VIEWS FROM THE SOUTH

Assessment and Curriculum in Higher Education: theory, cases, practices. Maidenhead: McGraw Hill

Barrie, S C (2007) A conceptual framework for the teaching and learning of generic graduate attributes. Studies in Higher Education 32(4) 439-58

Barrie, S C (2006) Understanding what we mean by the generic attributes of graduates. Higher Education 51(2) 215-41

Barrie, S C (2004) A research-based approach to generic graduate attributes policy. Higher Education Research and Development 23(3) 261-75

Botha, J (2009) Improvement-oriented evaluation of undergraduate science programmes and the quality of student learning. In Bitzer E (ed). Higher Education in South Africa. Stellenbosch: SUN MeDIA

Bowden, J, Hart, G, King, B, Trigwell, K and Watts, O (2000) Generic capabilities of ATN university graduates. http://www.clt.uts.edu.au/ATN.grad.cap.project.index.html [accessed June 2011]

Carr, D (2009) Revisiting the liberal and vocational dimensions of university education. British Journal of Education Studies 57(1) 1-7

DoBE (Department of Basic Education) (2010) Education statistics for South Africa 2009. www. education.gov.za [accessed June 2011]

DoE (Department of Education) (2001) National Plan for Higher Education in South Africa. http://education.pwv.gov.za/DoE_sites/Higher [accessed June 2011]

Du Plessis, A (2011) Results of Omega Questionnaire http://admin.sun.ac.za/trackwell/abqapqogq 0610/beheer.htm

Freire, P (1988) Pedagogy of the Oppressed. Translanted by Myra Bergman Ramos. New York: Continuum

Government Gazette no. 30353 (2007) The Higher Education Qualifications Framework

Griesel, H and Parker, B (2009) Graduate attributes: a baseline study on South African graduates from the perspective of employers. http://www.saqa.org.za/docs/pubs/general/graduate_attributes. pdf [accessed June 2011]

HEQC (2011) Framework for the second cycle of quality assurance 2012-2017: consultation document. http://www.che.ac.za/ [accessed June 2011]

Hughes, C and Barrie, SC (2010) Influences on the assessment of graduate attributes in higher education. Assessment and Evaluation in Higher Education 35(3) 325-34

James, B, Lefoe, G and Hadi, M(2004) Working 'through' graduate attributes: A bottom-up approach. HERDSA Conference proceedings http://www.herdsa.org.au/conference2004/ Contributions/RPapers/P022-jt.pdf (accessed June 2011)

Jansen, J (2009) Knowledge in the Blood. Cape Town: UCT Press

Killick, D (2008) Internationalisation: graduate attributes for a globalising world. Conference paper: Higher Education Academy Annual Conference, Harrogate, July.

Leibowitz, B (2011) How does the SU Graduate 2010 look? Voices from Students and Employers. Report to Stellenbosch University Senior Management Forum. Devonvale, February.

Levinson, M (2011) Democracy, accountability, and education. Theory and Research in Education 9(2) $125-44$

Mezirow, J (2003) Transformative learning as discourse. Journal of Transformative Education 1(1) 58-63

Musil, C (2003) Educating for citizenship. Peer Review. Spring 4-8

Musil, C (2011) Civic responsibility: new framing for a global century. Presentation at The CHECPGWC symposium on researching graduate quality. Cape Town, 14 March 
GRADUATE ATTRIBUTES FOR THE PUBLIC GOOD

Palmer, P (1987) Community, conflict, and ways of knowing: ways to deepen our educational agenda. Change Magazine 19(5) 20-5

SAQA (South African Qualifications Authority)(1997) SAQ A Bulletin 1(1), May/June

Soëtard, M (1994) Johann Heinrich Pestalozzi (1746-1827). Prospects: the quarterly review of comparative education XXIV (1/2) 297-310

SU [Stellenbosch University] (2011) Draft document: Hope as guiding concept for Stellenbosch University.

SU [Stellenbosch University] (2007a) Learning and teaching policy. http://stbweb02.stb.sun. ac.za/ctl/policies.html [accessed June 2011].

SU [Stellenbosch University] (2007b) Policy on teaching and learning materials. http://stbweb02. stb.sun.ac.za/ctl/policies.html [accessed June 2011]

SU [Stellenbosch University](2000) Strategic framework for the turn of the century and beyond. http://www.sun.ac.za/university/StratPlan/index.htm [accessed June 2011]

Van Schalkwyk, S, Cilliers, FJ, Adendorff, H, Cattell, K and Herman, N (2012) Journeys of growth towards the professional learning of academics: understanding the role of educational development. International Journal for Academic Development. DOI:10.1080/1360144X.2012. 673490

Waghid, Y (2009) Universities and public goods - in defense of democratic deliberation, compassionate imagining and cosmopolitan justice. In E Bitzer (ed) Higher Education in South Africa. Stellenbosch: SUN MeDIA

Waghid, Y (2005) On the possibility of an African university: towards a scholarship of criticism, deliberation and responsibility. South African Journal of Higher Education 19 1306-14

Walker, M (2002) Pedagogy and the politics and purposes of higher education. Arts and Humanities in Higher Education 1(43) 43-58

Willey K and Gardner A (2007) Assisting academics to use self and peer assessment processes to integrate graduate attribute development with discipline content delivery. Online. Available at www.sefi.be/wp-content/abstracts/1186.pdf (accessed June 2011) 